UDK: 331.45

DOI: https://doi.org/10.24867/11HZ02Bakic

\title{
PROCENA RIZIKA KAO INSTRUMENT ZA NADZOR BEZBEDNOSTI PROIZVODA NA TRŽIŠTU
}

\section{RISK ASSESSMENT AS AN INSTRUMENT FOR MONITORING THE SAFETY OF PRODUCTS ON THE MARKET}

\author{
Jelena Bakić, Milenko Sekulić, Fakultet tehničkih nauka, Novi Sad
}

\begin{abstract}
Oblast - INŽENJERSTVO ZAŠTITE NA RADU
Kratak sadržaj - Rad sadrži definicije osnovnih pojmova: bezbedan, obmanjujuci, opasan proizvod, opasnost, rizik $i$ slično. S obzirom da procena rizika predstavlja alat koji omogućava identifikaciju opasnih karakteristika proizvoda, veći deo rada posvećen je objašnjenju ovog alata $i$ prikazu koraka postupka procene rizika, kao $i$ analizi dve od mnogobrojnih metoda za procenu rizika. Dat je prikaz studije slučaja procene rizika na konkretnom primeru produžnog kabla, koji je okarakterisan kao nebezbedan. Pored negativnog primera, prikazuje i kompanije koje su u 2019. godini nagrađene za visok nivo bezbednosti svojih proizvoda.
\end{abstract}

Ključne reči: proizvod, opasnost, rizik, potrošač, bezbednost, procena rizika

\begin{abstract}
The paper contains definitions of basic terms: safe, deceptive, dangerous product, danger, risk and the like. Since risk assessment is a tool that allows the identification of hazardous product characteristics, most of the work is dedicated to explaining this tool and showing the steps of the risk assessment process, as well as analyzing two of the many methods for risk assessment. A case study of risk assessment is presented on a specific example of an extension cable, which is characterized as unsafe. In addition to the negative example, it also shows companies that were awarded in 2019 for a high level of safety of their products.
\end{abstract}

Keywords: product, dangerous product, risk, consumer, safety, risk assessment

\section{UVOD}

Bezbednost proizvoda je jedan od zahteva koji proizvođačima otvara ili zatvara vrata tržišta širom sveta. Zaštita potrošača u razvijenim zemljama orjentisana je na kvalitet i bezbednost proizvoda. Potrošači se moraju tačno informisati preko oglasnih sredstava o ispravnosti i bezbednosti proizvoda $\mathrm{i}$ to je vrlo bitan element zaštite potrošača. U cilju zaštite potrošača Evorpska unija je razvila tzv. RAPEX sistem za upozoravanje na proizvode koji nose neku vrstu rizika po zdravlje i bezbednost korisnika odnosno potrošača. Instrument koji se jako dobro pokazao za nadzor bezbednosti proizvoda na tržištu jeste procena rizika. Pored toga, procena rizika je važna za rad na bezbednosti proizvoda van tržišnih nadzornih

\section{NAPOMENA:}

Ovaj rad proistekao je iz master rada čiji mentor je bio dr Milenko Sekulić, red. prof. organa, odnosno, treba da je primenjuju i projektanti, konstruktori i proizvođači kao deo ocene usaglašenosti kojom se obezbeđuje da se na tržištu nađu samo bezbedni proizvodi. Takođe, rezultat procene rizika predstavlja input u postupku upravljanja rizikom. Svrha celokupnog postupka procene rizika jeste kontrola rizika.

\section{BEZBEDAN PROIZVOD}

\subsection{Osnovni pojmovi}

Bezbedan proizvod je svaki proizvod koji, pod redovnim ili razumno predvidljivim uslovima upotrebe, ne predstavlja nikakav rizik ili predstavlja minimalan rizik koji je primeren upotrebi proizvoda.

Opasan proizvod je svaki proizvod koji nosi neku opasnost po njegovog potrošača. Zadatak organa za nadzor tržišta je da povuče sa tržišta ovakav proizvod ukoliko se na njemu nađe.

Obmanjujući proizvod je svaki koji bojom, oblikom, ili bilo kojom drugom karakteristikom podseća na prehrambenim.

\subsection{Srbija i Evropska unija sa aspekta bezbednog proizvoda}

Republika Srbija trenutno osim usvojenih Zakona o opštoj bezbednosti proizvoda i Zakona o bezbednosti hrane, još uvek nema odgovarajuću praksu i procedure kojima bi se domaćim potrošačima garantovala opšta bezbednost svih proizvoda, kao ni prateće podzakonske propise.

Za prijem u Evropsku uniju potrebno je da Srbija, sprovede opsežne ekonomske, političke, pravne i administrativne reforme i usklađivanje svog sistema sa zahtevima Unije, u cilju uspostavljanja kompatibilnog društveno ekonomskog sistema sa tržišnom privredom, pravnom državom i demokratskim sistemom, u kome su svi građani jednaki pred zakonom i državnim organima i u kom se ne samo de jure nego i de facto poštuju ljudska prava i slobode građana.

\subsection{Lica koja nose odgovornost za bezbednost proizvoda}

Dug je put dolaska proizvoda u ruke potrošača. Potrošač očekuje da proizvod koji kupi ima određeni kvalitet koji podrazumeva pogodnost za upotrebu, ispravnost, sigurnost, pouzdanost.

Iz tih razloga svako ko učestvuje u lancu nabavke i plasmana na tržište $\mathrm{i}$ upotrebe proizvoda, mora snositi određenu odgovornost za proizvod. Učesnici u ovom 
lancu su: proizvođač, ovlašćeni zastupnik, uvoznik, distributer, montažer i korisnik/potrošač.

\section{POJAM RIZIKA}

Rizik se najčešće definiše kao potencijalna opasnost po ljude i materijalna dobra. Matematički može se posmatrati kao funkcija verovatnoće nastanka nekog neželjenog događaja i negativnih posledica koje može prouzrokovati taj neželjeni događaj.

$$
\mathrm{R}=\mathrm{F}(\mathrm{V}, \mathrm{P})
$$

$\mathrm{R}$ - rizik, V - verovatnoća nastanka neželjenog događaja, $\mathrm{P}$ - negativne posledice prouzrokovane neželjenim događajem.

Potrebno je naglasiti suštinsku razliku između rizika i opasnosti, jer se ta dva pojma često poistovećuju. Rizik predstavlja scenario u kom postoji verovatnoća materijalizacije štetnog događaja, zbog kog će nastati posledice po potrošača, dok je opasnost potencijalni izvor događaja koji te posledice stvara.

\subsection{Klasifikacija rizika}

Rizici sa kojima se susreću kompanije prilikom obavljanja svojih poslovnih operacija mogu biti rezultat delovanja spoljašnjih i unutrašnjih faktora. Rizike je moguće klasifikovati na: strategijske, finansijske, operativne i rizike kao posledica hazarda.

\subsection{Definicije opštih pojmova koji se tiču procene rizika}

Štetnost - fizička povreda, oštećenje zdravlja ljudi, oštećenje imovine ili oštećenje životne sredine.

Štetni događaj - pojava u kojoj opasna situacija ima za rezultat štetnost.

Opasnost - definiše se kao izvor mogućeg oštećenja. Može se reći da bez postojanja opasnosti ne postoji rizik.

Opasna situacija - okolnosti u kojima su ljudi, imovina ili životna sredina izloženi jednoj ili više opasnosti.

Prihvatljivi rizik - rizik koji se u datom kontekstu prihvata na osnovu sadašnjih vrednosti u društvu.

Nesreća - stvarna realizacija opasnosti. Još se definišu kao iznenadna, nenamerna odstupanja od normalnih uslova, u kojima je prouzrokovan neki stepen oštećenja.

Akcident - definiše se kao neplanirani događaj koji vodi ka mogućim povredama ili bolestima u vezi sa radom.

\section{PROCENA RIZIKA KAO INSTRUMENT ZA NADZOR BEZBEDNOSTI PROIZVODA NA TRŽIŠTU}

Procena rizika predstavlja postupak za određivanje nivoa rizik koji proizvod sa opasnim svojstvima predstavlja za ljude, životinje ili imovinu. Primenjuje se na konkretan proizvod a rezultat ovog postupka je postojeći nivo rizika koji može biti predmet daljih faza upravljanja.

Polazna tački za pokretanje postupka procene rizika može biti incident, prigovor potrošača, prijava proizvođača o problemu i slično. Takođe, organ koji vrši nadzor tržišta za proizvod koji izgleda opasno na prvi pogled može pokrenuti procenu rizika u svrhu provere bezbednosti tog proizvoda.

\subsection{Faze postupka procene rizika}

Kako proizvođač snosi odgovornost za bezbednost proizvoda, shodno tome i procena rizika je većim delom

njegova obaveza. Uvek je bolje da to izvrši manji tim od nekoliko stručnih lica, kako bi se izbegla subjektivnost pri ocenjivanju rizika. Sam postupak se može podeliti na nekoliko koraka i to:

Korak 1: Definisanje poizvoda koji je predmet procene.

Korak 2: Identifikacija opasnosti koje su prisutne.

Korak 3: Utvrđivanje ko su ugrožene vrste potrošača.

Korak 4: Opisivanje načina kako opasnost šteti potrošaču, što za rezultat ima dobijanje nekoliko scenarija povređivanja za jedan proizvod.

Korak 5: Kombinovanje vrste povrede i dela tela čime se procenjuje težina svakog scenarija povređivanja.

Korak 6: Određivanje verovatnoće svakog scenarija povređivanja (razlaganje na manje korake).

Korak 7: Kombinovanje težine povrede i verovatnoće njenog nastanka kako bi se dobio krajnji nivo rizika.

\subsubsection{Definisanje proizvoda}

Prvi korak u postupku procene rizika jeste identifikacija i definisanje proizvoda koji će biti predmet procene. To podrazumeva da podaci poput imena proizvoda, brenda, imena modela, mogući serijski broj proizvoda, zemlja porekla, pakovanje i slični, moraju biti poznati.

\subsubsection{Identifikacija opasnosti}

Opasnost je ta koja izaziva povredu lica koje koristi proizvod odnosno potrošača. Mogu se razlikovati:

- mehanička opasnost,

- opasnost od strujni udar,

- toplotna ili ili opasnost od požara,

- hemijska opasnost,

- mikrobiološka opasnost,

- opasnost od buke,

- druge opasnosti.

\subsubsection{Identifikacija ugroženih potrošača}

Kako bi se mogli odrediti ugroženi potrošači, iste je potrebno svrstati u određene kategorije. Tabela 1. daje prikaz klasifikacije potrošača.

Tabela 1. Klasifikacija potrošača/korisnika

\begin{tabular}{|c|c|}
\hline $\begin{array}{l}\text { Veoma vulnerabilna } \\
\text { lica }\end{array}$ & Vulnerabilna lica \\
\hline Slepa lica & Slabovida lica \\
\hline $\begin{array}{c}\text { Lica sa teškim telesnim } \\
\text { oštećenjima }\end{array}$ & $\begin{array}{l}\text { Lica sa delimičnim telesnim } \\
\text { oštećenjima }\end{array}$ \\
\hline $\begin{array}{l}\text { Veoma stara ili nemoćna } \\
\text { lica }\end{array}$ & $\begin{array}{c}\text { Starija lica sa delimičnim } \\
\text { slabljenjem njihovih mentalnih } \\
\text { i fizičkih sposobnosti }\end{array}$ \\
\hline $\begin{array}{l}\text { Vrlo mlada lica (ispod } 5 \\
\text { godina) }\end{array}$ & Mlada lica (5-11 godina) \\
\hline
\end{tabular}

\subsubsection{Povređivanje}

Opasnost kod potrošača može da izazove povrede koje 
mogu imati različite stepene težine. Ozbiljnost povrede tako odražava efekat opasnosti na potrošača i to je jedan od dva ključna parametra koji određuju nivo rizika.

\subsubsection{Određivanje težine povrede}

Kombinovanjem vrste povrede i dela tela na kom povreda može nastati određuje se težina svakog scenarija povređivanja. Zavisno od toga da li će doći do nastanka lakše povrede odnosno povrede koja ne iziskuje hospitalizaciju i lekarski nadzor ili onih ozbiljnijih koje zahtevaju hospitalizaciju, nivo ozbiljnosti povrede se kreće od 1 do 4.

\subsubsection{Verovatnoća nastanka povrede}

U mnogim slučajevima, najbolja je praksa proceniti verovatnoću svakog koraka. Ova procena je najveći izazov za lice koje vrši procenu i o njoj bi ukoliko je to moguće trebalo raspravljati unutar grupe stručnjaka. Konačni ishod procene rizika manje je osetljiv na promene verovatnoće kada je šteta koju proizvod može prouzrokovati veoma velika (npr. nesreća sa velikim i nepovratnim efektima). Drugi mogućnost je izvršiti jednu procenu vrednosti za ukupnu verovatnoću.

\subsubsection{Nivo rizika}

Ukupan nivo rizika predstavlja krajnji rezultat procene rizika. On može biti:

- OZBILJAN - zahteva brzu i nitnu akciju,

- UMEREN - zahteva određenu akciju,

- NIZAK - ne zahteva akciju kada su u pitanju proizvodi koji su već na tržištu.

Upotrebom podataka dobijenih iz prethodnih koraka do krajnjeg nivoa rizika dolazi se u tri koraka:

1. Upotreba tabele koja kombinuje dva glavna faktora koji utiču na procenu rizika, a to su ozbiljnost i verovatnoća nastanka povrede (štete).

2. Upotreba tabele za utvrđivanje nivoa prihvatljivog rizika za taj proizvod. Da li će taj rizik biti prihvatljiv zavisi od toga kojoj grupi korisnika pripada osoba koja koristi proizvod kao i od toga da li proizvod ima adekvatna upozorenja i zaštitne naprave, i da li je opasnost dovoljno očigledna.

3. U poslednjem koraku potrebno je uporediti procenjeni nivo rizika iz prve tabele sa prihvatljivim nivoima iz druge tabele kako bi se donela odluka o ukupnoj ozbiljnosti rizika, što će uticati na nivo neophodne korektivne akcije.

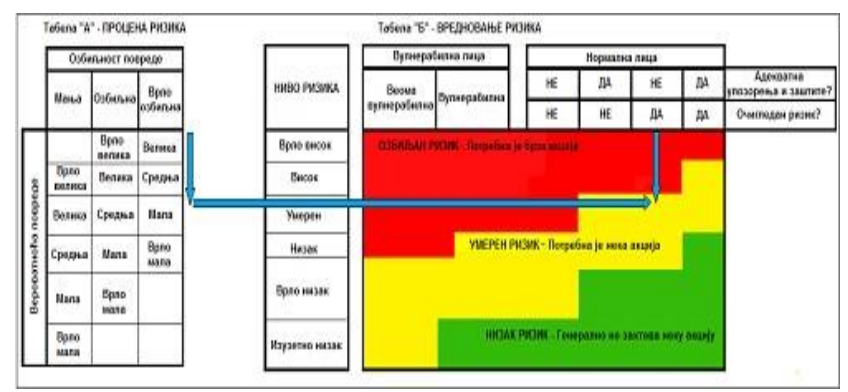

Slika 1. Ukupan nivo riizka

\subsection{Upravljanje rizikom}

Upravljanje rizikom podrazumeva proces identifikacije problema, kao i definisanja akcija vezanih za određivanje, ocenu, izbor, implementaciju, praćenje i modifikaciju aktivnosti preduzetih da redukuju rizik na prihvatljivi nivo.

\section{POSTUPAK OCENE USAGLAŠENOSTI I PROCENA RIZIKA}

Ocena usaglašenosti podrazumeva proveru da li dati proizvod ispunjava osnovne zahteve koji su obično utvrđeni direktivom ili precizirani harmonizovanim standardima.

Kada je u pitanju procena rizika, nadležni organ ili proizvođač može izvršiti ovaj postupak i kada se u pogledu proizvoda otkrije neka opasnost u cilju donošenja odluke o odgovarajućim merama za suzbijanje identifikovane opasnosti. Može biti instrument i pre ali i nakon stavljanja proizvoda na tržište.

\section{METODOLOGIJE KOJE SE KORISTE ZA PROCENU RIZIKA}

Postoji niz metoda koje se mogu primenjivati u postupku procene rizika. U zavisnosti od kriterijuma za procenu rizika sve metode koje se primenjuju dele se na: kvantitativne, kvalitativne, polukvantitativne.

\subsection{Kvalitativna metoda - matrica $3 \times 3$}

Matrica ima tri nivoa za kvalitativni opis verovatnoće neverovatno, verovatno i veoma verovatno. Isto tako i za opis posledice postoje tri nivoa - umerene, srednje i velike. Rizik se interpretira opisno kao: mali, srednji i veliki.

Karakteristike jedne ovakve metode su:

- mogućnost primene samo za identifikovane opasnosti/štetnosti (nije alat za identifikaciju opasnosti/štetnosti),

- veliki stepen subjektivnosti pri procenjivanju rizika i

- mogućnost samo komparativne, odnosno uporedne analize nivoa rizika.

\subsection{KINI (KINNEY) metoda}

Jedna od kvantitativnih metoda koja je dosta zastupljena kada je u pitanju procena rizika jeste KINNEY. Prema KINNEY metodi rizik se računa kao proizvod verovatnoće povređivanja, učestalosti i vremena izlaganja opasnostima i posledice koje su rezultat prisustva opasnosti.

\section{7. ŠTA NAKON PROCENE RIZIKA}

\subsection{Izveštaj o proceni rizika}

Nakon izvršenja postupka procene rizika, potrebno je dobijene rezultate evidentirati kako bi se mogli koristiti prilikom sprovođenja korektivnih postupaka. Iz tih razloga potrebno je formirati Izveštaj o proceni rizika. Forma izveštaja mora biti takva, da se u njemu nađu neophodne informacije (identifikacija proizvoda i predmeta, opis konteksta, opis opasnosti, opis scenarija povređivanja, zaključak - sadrži inedtifikovani nivo rizika).

\subsection{Korektivne mere}

Ukoliko se procenom rizika utvrdi da proizvod poseduje nebezbedne karakteristike, kompanija kako bi zaštitila svoje potrošače i sačuvala svoj imidž mora pokrenuti korektivne postupke. U okviru njih preduzimaju se sledeći 
koraci: povlačenje proizvoda iz lanca distribucije, dostavljanje korisnicima upozorenja o pravilnoj upotrebi proizvoda, promena dizajna proizvoda, vršenje izmena

proizvoda u prostorijama kupca ili na drugom mestu, povraćaj proizvoda od potrošača uz zamenu ili novčanu nadoknadu.

\subsection{Komunikacija sa javnošću}

Dve stvari koje će olakšati saopštavanje javnosti informacija o proceni rizika su:

Prihvatiti i javno priznati da je zajednica važna i da ima značajnu moć. Mnogo puta kompanije ne prepoznaju volju zajednice, što dovede do negativnog ishoda.

Biti vrlo oprezan i ne podrazumevati da je svako protivljenje zajednice tehnologiji iracionalno ili samo neuko. Nepoverenje javnosti prema nauci i razvoju nije uvek neosnovano. Ponovljeni skandali i bezosjećajna manipulacija podacima izazivaju pojavu nepoverenja javnosti.

\section{STUDIJE SLUČAJA}

\subsection{Produžni kabel sa tri utičnice i prekidačem}

Produžni kabel sa tri utičnice i prekidačem, dužine 2.9 metara, sa oblikovanim uzemljenim utikačem. Proizvod je prijavljen od strane Nemačke 2010. godine (RAPEKS obaveštenje 1520/10)

Opasnost: Proizvod predstavlja opasnost od strujnog udara, jer su kontaktne površine preslabe i već su deformisane, zbog čega nema kontakta između konektora za uzemljenje u utičnici i konektora za uzemljenje na utikaču. Ako je neispravan električni aparat povezan na ovaj kabel, neće biti povezan sa zaštitnim uzemljenjem. To znači da će korisnik zadobiti strujni udar kada dodirne kućište uređaja. Pored toga, poprečni presek provodnika u kablu za napajanje je premali i naponski provodnici su zalemljeni na kontaktne površine. Ako se uređaj sa velikom potrošnjom energije poveže preko produžnog kabla i koristi duže vreme, kablovi će se pregrejati i može se izazvati veći požar.

\section{NAGRADE ZA BEZBEDNOST PROIZVODA}

U februaru 2019. godine, dodeljene su nagrade EU za bezbednost proizvoda preduzećima koja po pitanju bezbednosti, prevazilaze minimalne zahteve sadržane $u$ zakonu EU. Nagrada promoviše kompanije koje čine sve da zaštite svoje kupce, dajući primer koji može inspirisati i druge. Pobednici su izabrani na osnovu četiri glavna kriterijuma: inovacije, uticaj, potencijal replikacije i procesi bezbednosti proizvoda.

\subsection{Zlatna nagrada}

Italijanska kompanija Remmy je 2013. godine razvila prvo upozorenje za bebe za automobile. Ovaj jednostavan, ali efikasan uređaj signalizira vozaču da je dete $u$ automobilu i kada je isti isključi. Isto tako u slučaju da sigurnosni pojas nije pravilno pričvršćen uređaj će se oglasiti.

\subsection{Srebrna nagrada}

Imajući na umu da su nesreće u stolicama vrlo česte kod male dece, pri čemu najčešće dolazi do prevrtanja stolice u nazad, norveški dizajner Peter Opsvik i kompanija Evomove stvorili su novu generaciju stolica za bebe tzv.
Nomi. Stolica poseduje poseban valjak koji sprečava naginjanje, a takođe je oblik stolice takav da su njene ivice zaobljene.

\subsection{Bronzana nagrada}

Treću nagradu za bezbednosti dobila je nemačka kompanija Reer. Duže vreme ova kompanija proizvodi sigurnosne uređaje vodeći računa o bezbednosti dece u kući. Takođe posvećuje pažnju i edukuje potrošača putem obrazovnih video zapisa, vodiča i kontrolnih lista.

\section{ZAKLJUČAK}

Procena rizika proizvoda je dobra metodologija koja se može primeniti u svrhu lakšeg dolaženja do zadovoljavajućeg nivoa bezbednosti proizvoda. Takođe, ovim postupkom se mogu uočiti potencijalne opasnosti na već lansiranim proizvodima na tržištu što je važno u smislu povlačenja nebezbednih proizvoda sa istog.

Naravno, svedoci smo da se u realnosti na tržištu pojavljuju proizvodi različitog kvaliteta i stepena bezbednosti. Cilj kom treba težiti u budućnosti je da se na tržištu nađu samo bezbedni i sigurni proizvodi, a da oni opet budu pristupačni svakom korisniku, a do tada "CAVEAT EMPTOR", odnosno neka kupac bude oprezan.

\section{LITERATURA}

[1] Bahr, N. J. (2014). System safety engineering and risk assessment. A practical approach. Florida, 2014.

[2] European Commission. 2019. Product safety award, Luxemburg, 2019.

http://www.zzs.gov.me/ResourceManager/FileDownload. aspx?rid=80303\&rType=2\&file=EMARS.pdf 25.08.2020.

[3] Selukić M. (2014). Bezbednost proizvoda i zaštita korisnika/potrošača. Skripta, FTN, Novi Sad,2014.

[4] Službeni glasnik Republike Srbije. 41/2009 i 77/2019. Zakon o opštoj bezbednosti proizvoda. Beograd: JP "Službeni glasnik".

\section{Kratka biografija:}
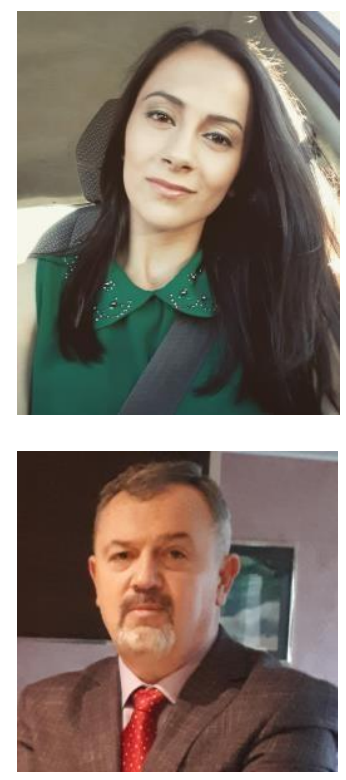

Jelena Bakić rođena je u Sremskoj Mitrovici 1996. god. Nakon završetka gimnazije, upisala je osnovne akademske studije na Fakultetu tehničkih nauka, smer Inženjerstva zaštite na radu. Diplomirala 19. septembra 2019. Iste godine upisala master akademske studije. Diplomu master inženjera stiče 2020. godine.

Prof. dr Milenko Sekulić, rođen je 1966. god. Na Fakultetu tehničkih nauka zaposlen je od 1994. god. i trenutno je u zvanju redovnog profesora. Uža oblast interesovanja obuhvata: tehnologije obrade skidanjem materijala, inovacione tehnologije obrade, modeliranje procesa obrade, dizajn proizvoda, bezbednost proizvoda i zaštitu korisnika/potrošača.. 